\title{
The hormonal composition of follicular fluid and its implications for ovarian cancer pathogenesis
}

\author{
Megan M Emori and Ronny Drapkin*
}

\begin{abstract}
Ovulation has long been associated with an increased risk in ovarian cancer, yet the underlying molecular mechanisms remain obscure. Two aspects of ovulation have been linked to ovarian cancer pathogenesis. The first is the impact of repetitive tissue injury and repair that occurs with each ovulatory event. The second is the release of follicular fluid that accompanies the follicular rupture and its effect on the ovarian and fallopian tube epithelial cells. Hormones are an important component of follicular fluid, which transiently bathes the ovarian surface and fallopian tube epithelium during ovulation. Much work has been done exploring the role of hormones in fertility, but some, such as estrogen, have also been implicated in the pathogenesis of ovarian and other cancers. Understanding the role of hormones within follicular fluid, as well as how they are altered in disorders which increase ovarian cancer risk, will enhance our ability to assess risk and develop preventative strategies. This review provides an in depth discussion of the logistics of using and studying follicular fluid in ovarian cancer research, and discusses the fluctuations in follicular fluid hormone levels during normal physiological processes versus conditions that increase ovarian cancer risk.
\end{abstract}

Keywords: Follicular fluid, Ovarian cancer, Hormones

\section{Background}

Despite our growing understanding of the cancer genome and the evolution of targeted therapies, ovarian cancer remains the most lethal gynecological malignancy in the Western world [1]. The clinical outcomes for this disease have not changed significantly over the past four decades, in large part due the lack of early detection tools and the almost inevitable emergence of chemoresistant disease [1]. Adding to the complexity of this cancer is its heterogenous nature. Although ovarian tumors can arise from three different cell types: epithelial cells, germ cells, and sex cord stromal cells, the vast majority of ovarian cancers are epithelial in nature. Even within epithelial ovarian cancers there exist various histologic subtypes and molecular subgroups. This has prompted the classification of epithelial ovarian cancers into two groups. Type I tumors, clearly linked to ovarian precursor lesions, encompass all histologic subtypes including low grade serous, endometriod, mucinous, and clear cell carcinomas. They are defined by their slow

\footnotetext{
* Correspondence: ronny_drapkin@dfci.harvard.edu

Department of Medical Oncology, Dana Farber Cancer Institute, Harvard Medical School, 450 Brookline Avenue, Boston, MA 02115, USA
}

growth and multiple genetic mutations. In contrast, Type II tumors are highly aggressive, confer a much poorer prognosis, and many have been linked to precursors arising from the fallopian tube epithelium. High Grade Serous Ovarian Cancer (HGSOC) is the most common of the Type II tumors. Type I and Type II tumors are also genomically distinct. Type I tumors are frequently associated with specific mutations in oncogenes such as $k-R A S$ and ARID1A [2]. In Type II tumors, TP53 is mutated in the vast majority of tumors (96-100\%) and appears to be the earliest genetic event in HGSOC. BRCA1 and BRCA2 mutation carriers are particularly susceptible to Type II tumors $[2,3]$.

While much work has been done to characterize the pathology and genetics of ovarian cancer, we still lack a basic understanding of the early events and causes of this disease. Our current understanding of the risks factors of HGSOC derives primarily from epidemiological data. Lifetime ovulation is positively correlated with HGSOC, and factors such as parity and birth control, which decrease lifetime ovulation, have a protective effect against HGSOC [4,5]. Establishing a molecular mechanism linking ovulation and HGSOC pathogenesis is critical to 
developing screening techniques and treatments for this disease.

\section{Models of ovarian cancer pathogenesis}

The origins of ovarian cancer are complex and still under debate. New theories suggest that different ovarian tumor subtypes have different origins, with the ovarian surface epithelium implicated in Type 1 tumors and fallopian tube secretory epithelial cells implicated in high grade serous ovarian cancer $[2,3,6]$. The adherent mesothelium of the ovary attracts both shed fallopian tube cells as well as endometriosis-derived Müllerian tissue, further blurring the lines of the ovary vs. Müllerian tissue debate [7].

Understanding the various cells of origin in ovarian cancer similarly informs our understanding of ovarian cancer pathogenesis. Several models have been posited to explain how epidemiological factors such as menstruation and ovulation may lead to ovarian cancer. A long standing hypothesis, often called the Incessant Ovulation Hypothesis, suggests that the repetitive wounding and healing of the ovarian surface epithelium and adjacent tubal epithelium that is induced by monthly ovulation increases cell proliferation and thus the likelihood of genomic instability which could lead to oncogenesis (Figure 1) [4]. Another hypothesis, known as the Gonadotropin hypothesis, implicates excessive direct and indirect stimulation of the ovarian surface epithelium by gonadotropins, leading to differentiation, proliferation, and ultimately malignant transformation (Figure 1) [5]. More recently, the Incessant Menstruation hypothesis suggests that repeated exposure to retrograde menstruation exposes the ovary and fallopian tube to reactive oxygen species and oxidative iron from the blood [8]. Lastly, several recent papers have focused on damage induced by inflammation-mediated factors found in the follicular fluid $[9,10]$. The recurring theme in all these hypotheses is the incessant ovulatory damage. This reinforces the importance of ovulation, but also makes it difficult to separate the impact of each hypothesis as they are physiologically interconnected. Women with altered steroid hormone levels, such as those with Polycystic Ovarian Syndrome (PCOS), tend to ovulate sporadically, while women who take oral contraceptives receive the protective benefits of both lowered gonadotropin levels and inhibited ovulation [5,11]. The average age of onset in ovarian cancer is postmenopausal, at age 63, when hormonal levels have shifted and ovulation has stopped [12]. Thus, an unanswered question that also remains is why menopause is so temporally important to the onset of the disease.

\section{Ovulation and follicular fluid}

Mature human follicles reach approximately $23 \mathrm{~mm}$ in diameter, yielding upwards of $5 \mathrm{~mL}$ of follicular fluid (FF) [13]. During ovulation, FF is released and bathes

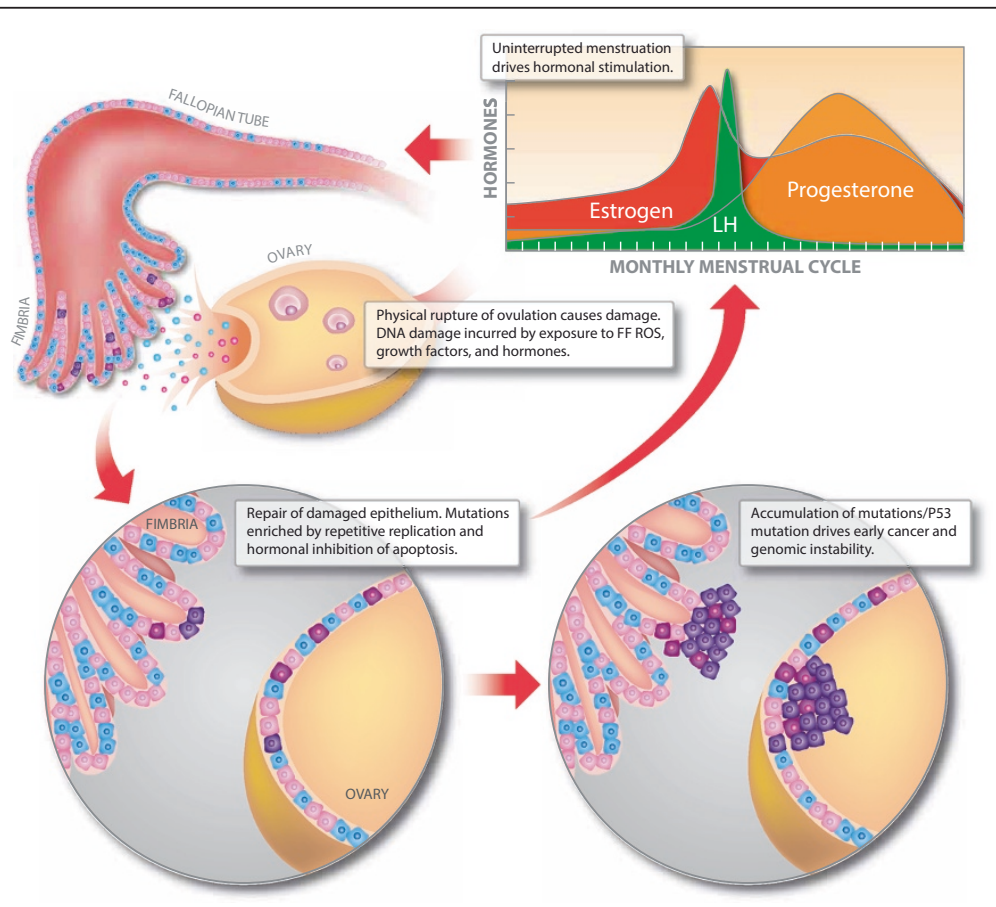

Figure 1 Proposed mechanisms of HGSOC pathogenesis. Incessant Ovulation Hypothesis: monthly physical damage from ovulation necessitates increased cell proliferation during repair, eventually leading to genomic instability. Gonadotropin hypothesis: Exposure to hormones released during ovulation inhibits natural apoptosis, uninterrupted hormonal fluctuations stimulate differentiation, proliferation, and ultimately malignant transformation. 
the surrounding tissue, including the ovarian surface epithelium and fallopian tube (FT) fimbria proximal to the ovary. The debate over whether the ovarian surface epithelium (OSE) or the FT fimbria is the cell of origin for HGSOC is discussed in detail elsewhere [6,14]. For the purposes of this review, both tissues are exposed to the risk factors associated with ovulation. While there is robust epidemiologic data correlating total ovulatory events to ovarian cancer risk, a biological explanation remains elusive. One possibility recently proposed is that FF is genotoxic to exposed epithelia (OSE and FTE) and that repetitive exposure to this fluid can lead to mutations and alterations that drive neoplastic transformation [15]. The composition of this fluid, known to play a critical role in the development of the follicle, has profound reproductive and pathogenic implications.

FF is initially derived from, and is similar in composition to, thecal capillary serum [16-18]. As the follicle develops, granulosa cells produce large polysaccharides, hormones, and growth factors which cannot pass the 100 kDA follicle-blood barrier, causing an osmotic gradient which further increases FF volume [19,20]. Ultimately, mature follicles in unstimulated women can contain as much as 1,000 fold higher levels of estrogen and progesterone than the serum, whereas other hormones such as follicle stimulating hormone (FSH) are not differentially concentrated [21]. Other potentially harmful factors, such as reactive oxygen species (ROS), have a physiologic window; their presence is required for embryo formation but particularly high levels within the FF are associated with poor embryo formation in IVF patients [22]. While FF components include hormones, fatty acids, inflammatory factors, reactive oxygen species, and growth factors, it is unclear what role these potentially antiapoptotic and mutagenic components play in ovarian cancer pathogenesis $[9,10,23]$.

\section{Follicular fluid sources}

Follicular fluid is often studied in the context of livestock reproduction, and abattoirs provide a readily available source of whole ovaries and fallopian tubes. While valuable research has been obtained using non-human models, the advantages of increased follicle volume and sample availability must be considered against the limited relevance of working with non-human FF [24]. Humans are the only known mammals to develop ovarian cancer naturally, and the levels of major hormones in cow and camel follicles is known to be several orders of magnitude lower than their human counterparts [25,26]. Domesticated laying hens, despite being oviparous, provide a unique model in that they are extremely susceptible to ovarian cancer and reflect several aspects of human disease [27]. Thus, a close examination of human FF, though harder to obtain and manipulate, is most relevant to studying the relationship between FF composition and ovarian cancer pathogenesis in humans.

Many recent studies have been conducted on the composition of human FF to assess conditions which are linked to ovarian cancer risk, as well as the efficacy and prognostic value of various in vitro fertilization (IVF) methods. This review gathers the most recent studies where human FF factors have been measured and comprehensively examines their fluctuation both under normal conditions and due to various conditions or treatments which are linked to HGSOC risk, and any role they may play in cancer pathogenesis (Table 1). Ultimately, developing a better understanding of FF and its hormonal composition will illuminate its potential role in ovarian cancer pathogenesis.

\section{The role of hormones in follicle development, fertility, and cancer pathogenesis \\ Estradiol \\ Function}

One of the most prominent components of FF, estradiol (E2), is dominant between the mid-follicular and preovulatory phases (Figure 1). Mouse models lacking E2 fail to develop mature follicles [28,29]. With regards to cancer, estradiol is also thought to have a mutagenic effect, particularly in female reproductive tissue where elevated blood levels of estrogens have been associated with an increased risk of breast and uterine cancer [30,31]. Since follicular fluid E2 concentrations can reach 1000 fold that of serum levels, estradiol may also play a role in HGSOC pathogenesis [21]. The two main oncogenic mechanisms proposed for estrogen are indirect stimulation of cell growth, leading to an increased risk of transcriptional errors, and direct generation of DNA damage, particularly through the production of free-radicals [32]. A detailed review of estrogen's direct and indirect mutagenic effects can be found elsewhere [31].

\section{Pathological and physiological conditions}

Studying E2 levels in women with reproductive abnormalities gives insight into infertility as well as long term cancer risk. Surprisingly, women with PCOS, known to have elevated serum E2 levels, showed no difference in their FF E2 when compared to male factor infertility controls [33]. Similarly, no difference in FF E2 was observed in women with endometriosis and male factor infertility controls [34].

The role of infertility in HGSOC risk versus the role of confounding infertility treatments is currently poorly understood. Studies measuring hormone levels in women who required large amounts of stimulation to ovulate and control subjects undergoing unstimulated In Vitro Fertilization (IVF) found that while older age decreased FF E2 levels, young low responders were comparable to control donors [21]. Further studies measuring FF E2 levels in women 
Table $1 \mathrm{FF}$ factors and their role in follicle development and cancer pathogenesis

\begin{tabular}{|c|c|c|c|}
\hline Factor & Role in follicle development & Potential role in pathogenesis & Mouse knockout model effect \\
\hline Estradiol & $\begin{array}{l}\text { Follicle development (specifically } \\
\text { mid-follicular to pre-ovulatory } \\
\text { phases) }[28,29]\end{array}$ & $\begin{array}{l}\text { Direct proliferatory effect [32], free radical generation [32], } \\
\text { epidemiological risk factor for breast and uterine cancers [30] }\end{array}$ & $\begin{array}{l}\text { Failure to develop mature } \\
\text { follicles [28] }\end{array}$ \\
\hline Progesterone & $\begin{array}{l}\text { End stage follicle development } \\
{[28,29]}\end{array}$ & $\begin{array}{l}\text { Progestin containing oral contraceptives decrease ovarian } \\
\text { cancer risk [41] }\end{array}$ & Failure to ovulate [28] \\
\hline Androgens & $\begin{array}{l}\text { Stimulates early follicle } \\
\text { development [28] }\end{array}$ & Unknown & $\begin{array}{l}\text { Decrease in fertility, } \\
\text { granulosa cell number [28] }\end{array}$ \\
\hline FSH & $\begin{array}{l}\text { Stimulation of primordial } \\
\text { follicles, dominant follicle } \\
\text { selection [45] }\end{array}$ & $\begin{array}{l}\text { Hormonal regulator of estrogen, progestrone, testosterone, } \\
\text { FSH and its signaling pathways highly expressed in OVCAR } \\
\text { cell lines }[46,51]\end{array}$ & $\begin{array}{l}\text { Failure to ovulate, failure of } \\
\text { primordial follicles to mature [46] }\end{array}$ \\
\hline$A M H$ & $\begin{array}{l}\text { Inhibits primordial follicle } \\
\text { growth [56]. }\end{array}$ & $\begin{array}{l}\text { Promotes growth and differentiation [54], elevated in granulosa cell } \\
\text { tumors [62]. Unlikely player in HGSOC as matched controls have no } \\
\text { difference in serum AMH, no correlation to stage or prognosis [63] }\end{array}$ & $\begin{array}{l}\text { Fertile but with shorter period } \\
\text { of fertility [56] }\end{array}$ \\
\hline$L H$ & $\begin{array}{l}\text { Supports thecal steroidogenesis, } \\
\text { induces ovulation and corpus } \\
\text { luteum formation [64] }\end{array}$ & $\begin{array}{l}\text { Promotes angiogenesis in EOC through PI3KAKT-mTOR pathway, } \\
\text { inhibits apoptosis and cisplatin mediated apoptosis in EOC }[69,70]\end{array}$ & $\begin{array}{l}\text { Atrophied ovaries, hypogonadism, } \\
\text { malformed antral follicles, no } \\
\text { corpus lutea [66] }\end{array}$ \\
\hline
\end{tabular}

undergoing standard IVF with low ovarian reserve confirmed that FF E2 levels decrease with age, but are higher in younger women with low ovarian reserve compared to control donors [35]. This is consistent with blood serum levels of estradiol, which decrease over a woman's reproductive life cycle and are lowest at menopause [36]. In general, it appears that in IVF stimulation suppresses the level of FF E2 as measured in young, healthy egg donors [37]. Unlike its clear role in uterine physiology and pathology, estrogen's contribution to ovarian cancer remains unclear and additional research is needed to define its role in this setting.

\section{Progesterone}

\section{Function}

The most abundant hormonal component of FF, progesterone (P4) is critical for the end stages of follicle development and for ovulation [29]. Knockout mice lacking progesterone fail to ovulate [38]. The role of progesterone is difficult to discern as increased levels of estrogen induce the production of progesterone receptors, inextricably linking their functions and responses [39]. Compared to E2, cellular responses to progesterone are much more diverse and therefore harder to implicate [40]. The molecular role of progesterone in HGSOC pathogenesis is unclear, but cumulative intake of specific exogenous progestins has no impact on risk except when combined with estrogen in oral contraceptives [41].

\section{Pathological and physiological conditions}

In the general population, it appears that age rather than infertility impacts FF P4 levels, and that P4 levels rise as a woman ages. In a study comparing low responders to control donors, P4 levels were the same between younger donors and young low responders, but higher in older low responders [21]. Similarly, young women with a normal ovarian reserve had lower FF P4 levels than their low ovarian reserve counterparts or older women [35]. Where follicular estrogen remained constant in both endometriosis and PCOS patients, follicular progesterone levels were markedly decreased in both groups [33,34].

In young, healthy egg donor populations, it appears that stimulating egg production has no effect on the FF P4 when compared to unstimulated donors [37]. However, in patients undergoing IVF, the current evidence is conflicting. The role of progesterone, while generally considered protective in breast cancer, remains unclear in the context of ovarian cancer.

\section{Androgens \\ Function}

Androgens, although predominantly involved in male development, are also expressed in the ovary and fallopian tube and play a critical role in early follicle development $[42,43]$. The role of androgens on follicle development is species dependent, and humans are the only mammal not known to exhibit a decrease in AR as the follicle matures $[28,33,44]$. Female mice lacking a functional androgen receptor (AR) are less fertile and have a shorter reproductive window $[42,43]$.

\section{Pathological and physiological conditions}

Unlike estrogen and progesterone, testosterone levels in mature follicles seem resistant to fluctuation, as women with infertility or IVF treatments are remarkably similar to their control counterparts. Follicular testosterone levels, uniquely to humans, continue rise as the follicle develops $[33,44]$. In patients with unstimulated cycles, testosterone was not significantly affected by age or responder status, with all patients comparable to donor controls [21]. As 
expected, when the mature follicles of women with PCOS were compared to women with male factor infertility, follicular testosterone levels were significantly higher in women with PCOS [33]. Stimulation in egg donors only slightly elevates the levels of FF testosterone as compared to their unstimulated donor controls [37].

\section{Follicle stimulating hormone Function}

FSH stimulates the development of primordial follicles and, through a feedback loop, maintains and selects the dominant follicle [45]. Mutant mice lacking the FSHreceptor are anovulatory. This is likely due to the fact that FSH blocks apoptosis in preantral follicles [46,47]. FSH-R knockout mouse models also lack circulating estrogen and have significantly less progesterone, while serum testosterone levels are increased, suggesting that FSH is also involved in hormonal regulation [46].

FSH serum levels rise at puberty and peak at menopause [45-47]. In younger women, high levels of serum FSH are indicative of ovary feedback dysfunction and are symptomatic of low ovarian reserve $[47,48]$. A notable exception to this is PCOS, where serum FSH levels are abnormally low [49].

\section{Pathological and physiological conditions}

Although follicular FSH is infrequently measured, it appears to be generally resistant to change. While one study confirmed that both women approaching menopause and young women who responded poorly to stimulation had high levels of follicular FSH, another found that neither ovarian reserve nor age altered FF FSH levels [21,35]. Although levels of follicular FSH have yet to be measured in PCOS patients, they do not appear to be affected by endometriosis [34]. Surprisingly, it is one of the few follicular hormones unaltered by IVF stimulation [37].

New research has emerged showing FSH to be highly elevated in a number of solid tumors. FSH is thought to be beneficial for oncogenesis in that it increases angiogenesis via the Vascular Endothelial Growth Factor (VEGF) pathway [50]. Given the rise of serum FSH in menopausal women that corresponds to the typical onset of ovarian cancer, it is worth noting that FSH has been shown to inhibit apoptosis in a variety of ovarian cancer subtypes in vitro [51]. One of the signaling pathways regulated by $\mathrm{FSH}, \mathrm{OCT} 4$, is also highly expressed in a variety of ovarian cancer cell lines and tumor samples, and has been shown to be involved in inhibiting apoptosis and inducing chemo-resistance, as well as stem cell regulation [52,53]. Less is known about the role of FSH within the follicle, but taken together these findings suggest that FSH may be a hormone of particular interest in the induction and growth of ovarian tumors.

\section{Anti-müllerian hormone}

\section{Function}

Anti-Müllerian hormone (AMH), is a transforming growth factor produced by the granulosa cells and involved in both growth and differentiation $[54,55]$. In the ovary, it functions to inhibit primordial follicle growth. AMH null mice are fertile and have fully developed ovaries but a much smaller fertility window [56]. AMH serum levels increase significantly in early childhood, peak in the early 20 s, then decline until becoming undetectable at menopause [55,57]. During the menstrual cycle, AMH decreases sensitivity to $\mathrm{FSH}$, and is negatively correlated with both FSH and estradiol [58-61] It is generally agreed upon that $A M H$ is a marker of follicle status and is not affected by fluctuations in other hormones [59].

\section{Pathological and physiological conditions}

Follicular levels of AMH closely mimic those of the serum, decreasing with age and decreased ovarian reserve, and negatively correlated with follicular FSH [35,61]. AMH has recently been identified as uniquely elevated in granulosa cell tumors, and is currently being evaluated as a marker to track the recurrence of this disease [62]. However, for the more common epithelial ovarian cancers, serum AMH does not appear to differ from that of agematched controls, nor does it correlate with stage of tumor or prognosis [63].

\section{Luteinizing hormone \\ Function}

Luteinizing hormone ( $\mathrm{LH})$ is produced by the anterior pituitary gland [64] and is responsible for supporting steroidogenesis within LH receptor positive thecal cells [65]. Mice who are deficient in LH are infertile, exhibit atrophied ovaries, and have low serum levels of estradiol and progesterone [66]. Surprisingly, serum FSH levels remain unaffected in these models [66]. Over the course of a woman's lifetime, serum LH levels will rise, peaking at menopause $[36,67,68]$.

\section{Pathological and physiological conditions}

While LH serum levels are known to rise at menopause [36,68], follicular fluid levels of LH remain surprisingly stable throughout the reproductive window. No difference was found in the LH follicular fluid levels between young and aging women in multiple studies [21,35]. Fertility status also appeared irrelevant to follicular LH levels, as low responders and women with reduced ovarian reserves of all ages had similar levels, even compared to their young, un-induced counterparts $[21,35]$. Another study comparing endometriosis patients to male infertility controls found no difference in follicular LH levels as well [34]. While comorbidities and aging do not seem to affect follicular LH levels, stimulation with $\mathrm{rFSH}$ and recombinant 
choriogonadotropin (rCG) significantly decreases LH levels within the follicle by approximately 100 fold [37].

Recently, LH has been implicated in epithelial ovarian cancer (EOC) as an enhancer of angiogenesis. Working through the PI3K/AKT-mTOR pathway, LH is capable of inducing VEGF, thereby implicating its involvement in cell growth, invasion, and migration [69]. LH has also been shown to upregulate survivin, inhibiting apoptosis in epithelial ovarian cancer [70]. Of particular interest is the fact that EOC cells treated with $\mathrm{LH}$ are much less sensitive to cisplatin induced apoptosis, suggesting a mechanism of drug resistance [70].

\section{Technical considerations}

While the microenvironment is critical to early ovarian cancer pathogenesis, several technical problems have plagued efforts to study it in detail. Access to follicular fluid features prominently on this list, as do lack of proper controls. For women who have been induced in the course of infertility treatments, multiple mature follicles and manual egg retrieval mean follicular fluid supply is plentiful, but at the expense of altered hormone levels. Oophorectomies, which often accompany hysterectomies, would provide a valuable source of unadulterated follicles except that these are generally performed later in life when the ovaries have atrophied. Very few experiments, with a few valuable exceptions, recruit young female volunteers for egg retrieval, severely limiting our knowledge of baseline hormonal composition $[20,36]$. Thus one of the main goals in this field should be to determine the separate risk factors of nulliparity and conditions which lead to infertility.

\section{Conclusions}

The hormonal profile of follicular fluid is complex and constantly in flux, changing dramatically over the course of follicle development, as well as throughout a woman's lifetime depending on her age, health status and fertility. Understanding the hormonal microenvironment of ovulation is critical to establishing a molecular link between incessant ovulation and early ovarian cancer pathogenesis. While studying the role of hormones in ovulation is important, no less important is the role of hormones in the transition to menopause, when ovarian cancer is typically diagnosed. Why this disease so often manifests itself after risk factors such as ovulation have come to an end, and when supposedly protective progesterone levels have risen and likely damaging estrogen levels are low is a puzzle at the crux of the ovarian cancer problem $[21,35]$. In the efforts to understand disease onset, cessation of ovulation and the hormonal milieu accompanying it will be as important as ovulation itself.

Currently, one of the most promising leads providing a molecular basis for the contribution of FF to ovarian cancer pathogenisis was reported by Bahar-Shany et al.
[15]. Using human fallopian tube ex-vivo cultures and pooled human FF, they found that exposing fallopian tube epithelium to FF stimulated inflammatory and DNA repair pathways and resulted in the upregulation of proangiogenic and pro-inflammatory interleukin 8 . They noticed that follicular fluid exposure led to DNA double stranded breaks and, consequently, the stabilization of the tumor suppressor TP53. Early precursors of high grade serous ovarian cancer are also defined by their high expression of TP53 and high levels of DNA damage, although in the vast majority of these cases TP53 is also mutated, often with a gain of function mutation [71]. Understanding the link between the temporary induction of TP53 in response to FF exposure and the aquisition of mutations in P53 in early precursor lesions will be key in the future of ovarian cancer research.

The role of hormones in the later stages of ovarian cancer is also a field ripe for study. The relationship between hormonal microenvironment and tumor is complicated, in no small part because the hormone receptors of many primary tumors and ovarian cancer cell lines have been inactivated either directly or indirectly. The lack of response to hormone signaling is evidenced by the largely unsuccessful use of hormonal therapy in ovarian cancer, especially compared to its sweeping successes in breast cancer [72,73].

In the fight against ovarian cancer, many factors beyond the hormonal milieu play a role, and follicular fluid is by no means the sole initiator of tumorigenesis. Other theories, including telomere shortening $[74,75]$ have been proposed as well. Ultimately, providing the molecular link between epidemiologic risk factors and disease mechanisms will have broad implications not only for ovarian cancer, but for infertility and development as well.

\section{Abbreviations}

AMH: Antimulerian hormone; AR: Androgen receptor; E2: Estradiol; EOC: Epithelial ovarian cancer; FF: Follicular fluid; FSH: Follicle stimulating hormone; FT: Fallopian tube; HGSOC: High grade serous ovarian cancer; IVF: In vitro fertilization; OSE: Ovarian surface epithelium; P4: Progesterone; PCOS: Polycystic ovarian syndrome; rLH: recombinant luteinizing hormone.

\section{Competing interests}

The authors declare that they have no competing interests.

\section{Authors' contributions}

ME reviewed the relevant literature and wrote the body of the manuscript. $\mathrm{RD}$ provided significant guidance in drafting and critically revising the manuscript. Both authors read and approved the final manuscript.

\section{Acknowledgements}

The authors would like to thank Dr. Daniel Cramer, Dr. Raymond Anchan, and Dr. Kevin Elias for providing valuable insight and helping to edit the manuscript, and Michael Cooper (Cooper Graphics: www.cooper247.com) for medical illustration. This work was supported by grants from the National Institutes of Health (U01 CA152990, R21 CA156021, and P50 CA083636), the Dr. Miriam and Sheldon G Adelson Medical Research Foundation, the Honorable Tina Brozman Foundation, the Robert and Debra First Fund, and the Gamel Family Fund. 
Received: 9 May 2014 Accepted: 27 June 2014

Published: 6 July 2014

\section{References}

1. Vaughan S, Coward JI, Bast RC, Berchuck A, Berek JS, Brenton JD, Coukos G, Crum CC, Drapkin R, Etemadmoghadam D, Friedlander M, Gabra H, Kaye SB, Lord CJ, Lengyel E, Levine DA, McNeish IA, Menon U, Mills GB, Nephew KP, Oza AM, Sood AK, Stronach EA, Walczak H, Bowtell DD, Balkwill FR: Rethinking ovarian cancer: recommendations for improving outcomes. Nat Rev Cancer 2011, 11:719-725.

2. Kurman RJ, Shih IM: The origin and pathogenesis of epithelial ovarian cancer: a proposed unifying theory. Am J Surg Pathol 2010, 34:433-443.

3. Karst AM, Drapkin R: Ovarian cancer pathogenesis: a model in evolution. J Oncol 2010, 2010:932371.

4. Fathalla MF: Incessant ovulation- a factor in ovarian neoplasia? Lancet 1971, 2:163.

5. Cramer DW, Welch WR: Determinants of ovarian cancer risk. II. Inferences regarding pathogenesis. J Natl Cancer Inst 1983, 71:717-721.

6. Levanon K, Crum C, Drapkin R: New insights into the pathogenesis of serous ovarian cancer and its clinical impact. J Clin Oncol 2008, 26:5284-5293.

7. Mandai M, Yamaguchi K, Matsumura N, Baba T, Konishi I: Ovarian cancer in endometriosis: molecular biology, pathology, and clinical management. Int J Clin Oncol 2009, 14:383-391.

8. Vercellini P, Crosignani P, Somigliana E, Vigano P, Buggio L, Bolis G, Fedele $L$ : The 'incessant menstruation' hypothesis: a mechanistic ovarian cancer model with implications for prevention. Hum Reprod 2011, 26:2262-2273.

9. Backman S, Kollara A, Haw R, Stein L, Brown T: Glucocorticoid-induced reversal of interleukin-1 $\beta$-stimulated inflammatory gene expression in human oviductal cells. PLoS One 2014, 9:e97997.

10. Lau A, Kollara A, St John E, Tone AA, Virtanen C, Greenblatt E, King W, Brown T: Altered expression of inflammation-associated genes in oviductal cells following follicular fluid exposure: implications for ovarian carcinogenesis. Exp Biol Med 2014, 239:24-32.

11. McCartney CR, Eagleson CA, Marshall JC: Regulation of gonadotropin secretion: implications for polycystic ovary syndrome. Semin Reprod Med 2002, 20:317-326.

12. Yancik R, Ries LG, Yates JW: Ovarian cancer in the elderly: an analysis of surveillance, epidemiology, and end results program data. Am J Obstet Gynecol 1986, 154:639-647.

13. Bächler M, Menshykau D, De Geyter C, Iber D: Species-specific differences in follicular antral sizes result from diffusion-based limitations on the thickness of the granulosa cell layer. Mol Hum Reprod 2014, 20:208-221.

14. Auersperg N: Ovarian surface epithelium as a source of ovarian cancers: unwarranted speculation or evidence-based hypothesis? Gynecol Oncol 2013, 130:246-251.

15. Bahar-Shany K, Brand H, Sapoznik S, Jacob-Hirsch J, Yung Y, Korach J, Perri T, Cohen Y, Hourvitz A, Levanon K: Exposure of fallopian tube epithelium to follicular fluid mimics carcinogenic changes in precursor lesions of serous papillary carcinoma. Gynecol Oncol 2014, 132:322-327.

16. Jiang JY, Macchiarelli G, Miyabayashi K, Sato E: Follicular microvasculature in the porcine ovary. Cell Tissue Res 2002, 310:93-101.

17. Carson R, Findlay J, Mattner P, Brown B: Relative levels of thecal blood flow in atretic and non-atretic ovarian follicles of the conscious sheep. Aust J Exp Biol Med Sci 1986, 64:381-387.

18. Rodgers RJ, Irving-Rodgers HF: Formation of the ovarian follicular antrum and follicular fluid. Biol Reprod 2010, 82:1021-1029.

19. Shalgi $R$, Kracier $P$, Rimon A, Pinto M, Soferman N: Proteins of human follicular fluid: the blood-follicle barrier. Fertil Steril 1973, 48:109-118.

20. Garzo VG, Dorrington JH: Aromatase activity in human granulosa cells during follicular development and the modulation by follicle-stimulating hormone and insulin. Am J Obstet Gynecol 1984, 148:657-662.

21. De los Santos MJ, Garcia-Laez V, Beltran D, Labarta E, Zuzuarregui JL, Alama P, Gamiz P, Crespo J, Bosch E, Pellicer A: The follicular hormonal profile in low-responder patients undergoing unstimulated cycles: is it hypoandrogenic? Hum Reprod 2013, 28:224-229.

22. Jana SK, Babu KN, Chattopadhyay R, Chakravarty B, Chaudhury K: Upper control limit of reactive oxygen species in follicular fluid beyond which viable embryo formation is not favorable. Reprod Toxicol 2010, 29:447-451.

23. Agarwal A, Saleh RA, Bedaiwy MA: Role of reactive oxygen species in the pathophysiology of human reproduction. Fertil and Steril 2003, 79:829-843.
24. King SM, Hilliard TS, Wu LY, Jaffe RC, Fazleabas AT, Burdette JE: The impact of ovulation on fallopian tube epithelial cells: evaluating three hypotheses connecting ovulation and serous ovarian cancer. Endocr Relat Cancer 2011, 18:627-642

25. Ghoneim IM, Waheed MM, El-Bahr SM, Alhaider AK, Al-Eknah MM: Comparison of some biochemical and hormonal constituents of oversized follicles and preovulatory follicles in camels (Camelus dromedarius). Theriogenology 2013, 79:647-652.

26. Walsh SW, Matthews D, Browne JA, Forde N, Crowe MA, Mihm M, Diskin M, Evans AC: Acute dietary restriction in heifers alters expression of genes regulating exposure and response to gonadotropins and IGF in dominant follicles. Anim Reprod Sci 2012, 133:43-51.

27. Johnson PA, Giles JR: The hen as a model of ovarian cancer. Nat Rev Canc 2013, 13:432-436.

28. Drummond AE: The role of steroids in follicular growth. Reprod Biol Endocrinol 2006, 4:16.

29. Gougeon A: Human ovarian follicular development: from activation of resting follicles to preovulatory maturation. Ann Endocrinol (Paris) 2010, 71:132-143.

30. Feigelson HS, Henderson BE: Estrogens and breast cancer. Carcinogenesis 1996, 17:2279-2284.

31. Cavalieri E, Frenkel K, Liehr JG, Rogan E, Roy D: Estrogens as endogenous genotoxic agents- DNA adducts and mutations. J Natl Cancer Inst Monogr 2000, 27:75-94.

32. Liehr JG: Is estradiol a genotoxic mutagenic carcinogen? Endocr Rev 2000, 21:40-54.

33. De Resende LO, Vireque AA, Santana LF, Moreno DA, De Sa Rosa e Silva AC, Ferriani RA, Scrideli CA, Reis RM: Single-cell expression analysis of BMP15 and GDF9 in mature oocytes and BMPR2 in cumulus cells of women with polycystic ovary syndrome undergoing controlled ovarian hyperstimulation. J Assist Reprod Genet 2012, 29:1057-1065.

34. Du YB, Gao MZ, Shi Y, Sun ZG, Wang J: Endocrine and inflammatory factors and endometriosis-associated infertility in assisted reproduction techniques. Arch Gynecol Obstet 2013, 287:123-130.

35. Pacella L, Zander-Fox DL, Armstrong DT, Lane M: Women with reduced ovarian reserve or advanced maternal age have an altered follicular environment. Fertil and Steril 2012, 98:986-994.

36. Sherman BM, West $\mathrm{JH}$, Korenman SG: The menopausal transition: analysis of $\mathrm{LH}, \mathrm{FSH}$, estradiol, and progesterone concentrations during menstrual cycles of older women. J Clin Endocrinol Metab 1976, 42:629-636.

37. De los Santos MJ, Garcia-Laez V, Beltran-Torregrosa D, Horcajadas JA, Martinez-Conejero JA, Esteban FJ, Pellicer A, Labarta E: Hormonal and molecular characterization of follicular fluid, cumulus cells and oocytes from pre-ovulatory follicles in stimulated and unstimulated cycles. Hum Reprod 2012, 27:1596-1605.

38. Lydon JP, DeMAyo FJ, Funk CR, Mani SK, Hughes AR, Montgomery CA Shyamala G, Conneely OM, O'Malley BW: Mice lacking progesterone receptor exhibit pleiotropic reproductive abnormalities. Genes Dev 1995, 9:2266-2278.

39. Kastner P, Krust A, Turcotte B, Stropp U, Tora L, Gronemyer H, Chambon P: Two distinct estrogen-regulated promoters generate transcripts encoding the two functionally different human progesterone receptor forms $\mathrm{A}$ and B. EMBO J 1990, 9:1603-1614.

40. Kim JJ, Kurita T, Bulun SE: Progesterone action in endometrial cancer, endometriosis, uterine fibroids, and breast cancer. Endocr Rev 2013, 34:130-162.

41. Faber MT, Jensen A, Frederiksen K, Glud E, Hogdall E, Hogdall C, Blaakaer J, Kjaer SK: Oral contraceptive use and impact of cumulative intake of estrogen and progestin on risk of ovarian cancer. Cancer Causes Control 2013, 24:2197-2206.

42. Hu YC, Wang PH, Yeh S, Wang RS, Xie C, Xu Q, Zhou X, Chao HT, Tsai MY, Chang C: Subfertility and defective folliculogenesis in female mice lacking androgen receptor. Proc Natl Acad Sci U S A 2003, 101:1209-1214.

43. Lyon MF, Glenister PH: Reduced reproductive performance in androgenresistant Tfm/Tfm female mice. Proc $R$ Soc Lond B Biol Sci 1979, 208:1-12.

44. Hillier SG, Tetsuka M: Role of androgens in follicle maturation and atresia. Baillieres Clin Obstet Gynaecol 1997, 11:249-260.

45. Hillier SG: Current concepts of the roles of follicle stimulating hormone and luteinizing hormone in folliculogenesis. Hum Reprod 1994, 9:188-191.

46. Danilovich N, Babu PS, Xing W, Gerdes M, Krishnamurthy H, Sairam MR: Estrogen deficiency, obesity, and skeletal abnormalities in follicle- 
stimulating hormone receptor knockout (FORKO) female mice. Endocrinology 2000, 141:4295-4308.

47. Sherman BM, Korenman SG: Hormonal characteristics of the human menstrual cycle throughout reproductive life. J Clin Investig 1975, 55:699-706

48. Slovis $\mathrm{BH}$, Check JH: Younger women with diminished oocyte reserve are not more prone to meiosis errors leading to spontaneous abortion than their age peers with normal oocyte reserve. Clin Exp Obstet Gynecol 2013, 40:29-32.

49. Chakrabarti J: Serum leptin level in women with polycystic ovary syndrome: correlation with adiposity, insulin, and circulating testosterone. Ann Med Health Sci Res 2013, 3:191-196.

50. Siraj A, Desestret V, Antoine M, Fromont G, Huerre M, Sanson M, Camparo P, Pichon C, Planeix F, Gonin J, Radu A, Ghinea N: Expression of folliclestimulating hormone receptor by the vascular endothelium in tumor metastases. BMC Cancer 2013, 13:246.

51. Tao X, Zhao N, Jin H, Zhang Z, Liu Y, Wu J, Bast RC, Yu Y, Feng Y: FSH enhances the proliferation of ovarian cancer cells by activating transient receptor potential channel C3. Endocr Rel Cancer 2013, 20:415-429.

52. Mak VC, Siu MK, Wong OG, Chan KK, Ngan HY, Cheung AN: Dysregulated stemness-related genes in gynecological malignancies. Histol Histopathol 2012, 27:1121-1130.

53. Zhang Z, Zhu Y, Lai Y, Wu X, Feng Z, Yu Y, Bast RC, Wan X, Xi X, Feng Y: Follicle-stimulating hormone inhibits apoptosis in ovarian cancer cells by regulating the OCT4 stem cell signaling pathway. Int J Oncol 2013, 43:1194-1204

54. Visser JA, De Jong FH, Laven JS, Themmen AP: Anti-mullerian hormone: a new marker for ovarian function. Reproduction 2006, 131:1-9.

55. Carlsson IB, Scott JE, Visser JA, Ritvos O, Themmen AP, Hovatta O: Antimullerian hormone inhibits initiation of growth of human primordial ovarian follicles in vitro. Hum Reprod 2006, 21:2223-2227.

56. Durlinger AL, Gruijters MJ, Kramer P, Karels B, Kumar TR, Matzuk MM, Rose UM, De Jong FH, Uilenbroek JT, Grootegoed JA: Anti-mullerian hormone attenuates the effects of FSH on follicle development in the mouse ovary. Endocrinology 2001, 142:4891-4899.

57. Kelsey TW, Wright P, Nelson SM, Anderson RA, Wallace WH: A validated model of serum anti-mullerian hormone from conception to menopause. PLoS One 2011, 6:e22024

58. Jeppesen JV, Anderson RA, Kelsey TW, Christiansen SL, Kristensen SG, Jayaprakasan K, Raine-Fenning N, Campbell BK, Yding Andersen C: Which follicles make the most anti-mullerian hormone in humans? Evidence for an abrupt decline in AMH production at the time of follicle selection. Mol Hum Reprod 2013, 19:519-527.

59. Fanchin R, Schonauer LM, Righini C, Frydman N, Frydman R, Taieb J: Serum anti-mullerian hormone dynamics during controlled ovarian hyperstimulation. Hum Reprod 2003, 18:328-332.

60. Durlinger AL, Kramer P, Karels B, De Jong FH, Uilenbroek JT, Grootegoed JA, Themmen AP: Control of primordial follicle recruitment by anti-müllerian hormone in the mouse ovary. Endocrinology 1999, 140(12):5789-5796.

61. Anckaert E, Smitz J, Schiettecatte J, Klein BM, Arce JC: The value of anti-Mullerian hormone measurement in the long GnRH agonist protocol: association with ovarian response and gonadotropin-dose adjustments. Hum Reprod 2012, 27:1829-1839.

62. Geerts I, Vergote I, Neven P, Billen J: The role of inhibins B and antimullerian hormone for diagnosis and follow-up of granulosa cell tumors. Int $\mathrm{J}$ Gynecol Canc 2009, 19:847-855.

63. Walentowicz P, Sadlecki P, Krintus M, Sypniewska G, Mankowska-Cyl A, Grabiec M, Walentowicz-Sadlecka M: Serum anti-mullerian hormone levels in patients with epithelial ovarian cancer. Int J Endocrinol 2013, 2013:517239.

64. Fevold $\mathrm{HL}$, Hisaw FL, Leonard SL: The gonad stimulating and the luteinizing hormones of the anterior lobe of the hypophesis. Am J Physiol 1931, 97:291-301.

65. Baird DT, Swanston IA, McNeilly AS: Relationship between LH, FSH, and prolactin concentration and the secretion of androgens and estrogens by the preovulatory follicle in the ewe. Biol Reprod 1981, 24:1013-1025.

66. Ma X, Dong Y, Matzuk MM, Kumar TR: Targeted disruption of luteinizing hormone $\beta$-subunit leads to hypogonadism, defects in gonadal steroidogenesis, and infertility. Proc Natl Acad Sci U S A 2004, 101:17294-17299.

67. Chada M, Prusa R, Bronsky J, Pechova M, Kotaska K, Lisa L: Inhibin B, follicle stimulating hormone, luteinizing hormone, and estradiol and their relationship to the regulation of follicle development in girls during childhood and puberty. Physiol Res 2003, 52:341-346.

68. Brodowska A, Laszczynska M, Brodowski J, Masiuk M, Starczewski A: Analysis of pituitary gonadotropin concentration in blood serum and immunolocalization and immunoexpression of follicle stimulating hormone and luteinising hormone receptors in ovaries of postmenopausal women. Histol Histopathol 2012, 27:241-248.

69. Liao H, Zhou Q, Gu Y, Duan T, Feng Y: Luteinizing hormone facilitates angiogenesis in ovarian epithelial tumor cells and metformin inhibits the effect through mTOR signaling pathway. Oncol Rep 2012, 27:1873-1878.

70. Zhang Z, Liao H, Chen X, Zheng Y, Liu Y, Tao X, Gu C, Dong L, Duan T, Yang Y, Liu $X$, Feng $Y$ : Luteinizing hormone upregulates survivin and inhibits apoptosis in ovarian epithelial tumors. Eur J Obstet Gynecol Repod Biol 2011, 155:69-74.

71. Lee Y, Miron A, Drapkin R, Nucci MR, Medeiros F, Saleemuddin A, Garber J, Birch C, Mou H, Gordon RW, Cramer DW, McKeon FD, Crum CP: A candidate precursor to serous carcinoma that originates in the distal fallopian tube. J Pathol 2007, 211:26-35.

72. Sjoquist K, Martyn J, Edmondson R, Friedlander M: The role of hormonal therapy in gynecological cancers-current status and future directions. Int J Gynecol Cancer 2011, 21:1328-1333.

73. Chumsri S, Howes T, Bao T, Sabnis G, Brodie A: Aromatase, aromatase inhibitors, and breast cancer. J Steroid Biochem Mol Biol 2011, 125:13-22.

74. Martinez-Delgado B, Yanowsky K, Inglada-Perez L, de la Hoya M, Caldes T, Vega A, Blanco A, Martin T, Gonzalez-Sarmiento R, Blasco M, Robledo M, Urioste M, Song H, Pharoah P, Benitez J: Shorter telomere length is associated with increased ovarian cancer risk in both familial and sporatic cases. J Med Genet 2012, 49:341-344.

75. Murakami J, Nagai N, Ohama K, Tahara H, Ide T: Telomerase activity in ovarian tumors. Cancer 1997, 80:1085-1092.

doi:10.1186/1477-7827-12-60

Cite this article as: Emori and Drapkin: The hormonal composition of follicular fluid and its implications for ovarian cancer pathogenesis. Reproductive Biology and Endocrinology 2014 12:60.

\section{Submit your next manuscript to BioMed Central and take full advantage of:}

- Convenient online submission

- Thorough peer review

- No space constraints or color figure charges

- Immediate publication on acceptance

- Inclusion in PubMed, CAS, Scopus and Google Scholar

- Research which is freely available for redistribution 